\title{
La Descuartizadora
}

\section{The Ripper}

\section{Jhon Camilo Rico Orjuela}

Estudiante Literatura

Universidad Autónoma de Bucaramanga

jrico2@unab.edu.co

Artículo recibido el 17 de octubre 2014

\section{Artículo aprobado el 27 de octubre 2014}

Puerto Azul era un pueblo demasiado pequeño en la década de los ochenta como para que en menos de un mes hubiesen aparecido las partes de dos hombres esparcidas en diferentes partes del hasta entonces acogedor puerto del Amazonas. En una comunidad que no sobrepasaba los mil habitantes, en donde la tasa de muertes violentas era casi nula, todos sus pobladores se conocían y cualquier acontecimiento como matrimonios, primeras comuniones, grados, nacimientos y fallecimientos por muerte natural, se convertían en noticia que transmitían en la única emisora y medio de comunicación Azul Estéreo.

El inicio de las fiestas de San Pedro se vio enlutado por la aparición en la mañana de tres cajas de cartón decoradas como regalos, con un gran moño rojo, en tres diferentes lugares; la primera apareció en la puerta del billar, la tarjeta decía para Mercedes, de su amor secreto.

Mercedes Barrera era la encargada del bar en el sitio, una joven de aproximados 25 años, hija de don Juan Manuel Barrera y la señora Leonor Prieto. La tercera de cinco hermanos, bachiller del colegio parroquial, de contextura gruesa sin ser obesa, piel canela, cabello negro rizado; gustaba de arreglarse de forma un tanto exagerada y poco recatada, situación que molestaba a sus padres y a su hermana la monja. Era soltera aunque no le faltaban pretendientes, sin embargo se rumoraba que salía con un hombre casado de un pueblo vecino y se encontraban la noche de los jueves que era su día libre.

La segunda caja apareció frente a la escuela de primaria igualmente bien decorada con un gran moño blanco y decía para la profesora Matilde del correcto amor.

Matilde Salcedo era maestra de la escuela desde que se graduó en la normal para señoritas de Camino 
Verde, era una mujer de 41 años, tenía dos hijos con su esposo, el dueño de la droguería del pueblo, el Farmaceuta Jacinto Poveda, quien llevaba alrededor de una semana desaparecido. Todos pensaban que se había ido con alguna jovencita del prostíbulo ubicado a la salida o de otro pueblo pues su fama de mujeriego era grande.

La tercera caja apareció igualmente decorada con vistoso papel regalo y un gran moño verde frente a la puerta de la viuda Magdalena Solís, una mujer de unos 50 años, su esposo había fallecido de un infarto hacia aproximadamente unos seis meses y su único hijo, estaba en el seminario; solo la acompañaban sus pájaros. La tarjeta decía para la viudita de su pícaro amor.

A Mercedes y a Matilde les avisaron en sus casas las personas que pasaban por ahí para que fueran a recoger sus llamativos regalos y la viuda cuando salía para la misa lo encontró, en los tres puntos del pueblo estaban los acompañantes de rigor, impregnados de la lógica curiosidad repetían en voz baja:

-¿que habrá dentro?

-¿quién lo envió?

Las tres mujeres, Mercedes, Matilde y Magdalena casi de forma simultánea destaparon sus obsequios, en el interior había una nevera de icopor, expectantes levantaron la tapa y al lado de un gran pedazo de hielo vieron partes de un ser humano. El horror las invadió tanto a ellas como a sus acompañantes.

La gente empezó a gritar por la calles, se cogían la cabeza a dos manos, y llegaron en menos de dos minutos a la estación de policía tres grupos de alborotados lugareños gritaban, el muerto, pedazos, regalo, la profesora Matilde, Merceditas la del billar, la pobre viuda Solís. El comandante Barbosa no entendía así que decidió enviar a dos gendarmes con cada grupo y el quedarse a cargo de la estación. Pues no contaban con más personal, jamás lo habían necesitado.

Cuando llegaron Pérez y Sánchez la profesora Matilde seguía desmayada, y empezaron a escuchar las versiones de sus curiosos acompañantes. En el billar Mercedes no paraba de vomitar a un lado de la calle entre sollozos, igualmente Rodríguez y Barragán tomaron declaraciones de las personas que la acompañaban. Y en la casa de doña Magdalena, ella sentada en la entrada con sus ojos clavados en el vacío, parecía, que no entendía, no escuchaba, no podía hablar, los vecinos explicaron a los gendarmes Tovar y Quintero como ocurrió todo.

Pérez, se dirigió a la morgue del centro de salud para que el forense colaborara recogiendo lo que ellos inicialmente pensaban eran tres cadáveres. Pasaron por la funeraria de don Pepe para que prestara el carro fúnebre para recoger los tres necro regalos, todo el pueblo estaba divido entre la escuela, el billar, la estación de policía, el puesto de salud y la casa de la viuda Solís. Todos habían olvidado las fiestas patronales, la misa, de San Pedro, el concierto de la noche, la cabalgata. El estupor y la intriga de saber quiénes eran los muertos. 
Aunque se rumoraba que los restos que recibió la profesora Matilde dieron el primer indicio, pues su esposo Jacinto llevaba una semana sin abrir la droguería y no había vuelto por la casa.

Dos horas después don Pepe, el doctor Montesinos y los gendarmes ya habían llevado las cajas con los tres supuestos cadáveres a la morgue. Todo estaban en manos del forense ahora, el que llevaba veinte años en el pueblo, que sentía que su trabajo en Puerto Azul era la mejor forma de retirarse pues sus días pasaban en medio del cálido clima rivereño y la tranquilidad de una población alegre y confiada. Revivir sus años como forense en la capital no era que le llamara mucho la atención pero era su deber y todo el pueblo esperaba lo mejor de él.

Hacia las diez de la mañana todos estaban recogidos en sus casas rezando el rosario. Las calles vacías, los negocios cerrados, era como un Viernes Santo. Mercedes, Matilde y Magdalena estaban respondiendo el interrogatorio correspondiente en la estación de policía. El comandante Barbosa ya se había comunicado con la capital para solicitar una comisión de la fiscalía que apoyara la investigación.

Tres mujeres atormentadas por un regalo mañanero, tres mujeres que permanecían la mayor parte de su tiempo solas, tres mujeres que compartían sin saber el secreto de un fallecido.

Hacia las cuatro de la tarde el doctor Montesinos salió de la morgue y se dirigió a la estación de policía a medida que avanzaba por las calles la gente empezaba a seguirlo y a preguntarle:

-¿quiénes eran los muertos?

-¿qué paso?

-¿cómo los mataron?

Montesinos con el ceño fruncido miraba a todos lados pero no soltaba palabra. Entro como alma que lleva el diablo a la estación, allí aún aturdidas seguían las tres Emes, como empezaron a llamar desde ese día a Mercedes, Matilde y Magdalena. Las miró y las saludo. El comandante lo esperaba, y le pidió que pasara a su oficina para hablar a puerta cerrada. Allí Dr. Montesinos le dijo, traje un informe preliminar porque todo el pueblo esta deshecho, antes de que empezará a leer el informe, llegó el Alcalde Amelines, también llegó el secretario del juzgado para tomar nota, pues el juez había viajado a un curso; completos todos, dieron inicio la diligencia:

Los antecedentes relacionaros tres cajas de cartón dejadas antes del amanecer, debidamente forradas en papel regalo y adornadas con moños de cintas de diferente color, tres tarjetas escritas en máquina con tres diferentes leyendas. En el interior de cada caja se encontró una nevera de icopor con hielo y partes de un ser humano, un solo ser humano, repartido en regalos para tres mujeres.

El comandante asentó, bueno ya no son tres muertos es solo uno, pero esto jamás había pasado acá, una persona descuartizada. 
Continuó el Dr. Montesinos: En la caja uno se halló un pie, una pierna completa un brazo con su mano, una oreja, restos de cabello, una nalga, cuatro costillas el intestino grueso, el colon y el recto, dos muelas y un colmillo, un carnet de farmaceuta a nombre de Jacinto Poveda acompañado de un testículo que al parecer había sido macerado, en una bolsa pequeña. Esta caja fue encontrada frente al billar las "Las Bolas del Puerto", con una tarjeta dirigida a la señorita Mercedes Barrera, con la anotación de su amor secreto, con un moño de color rojo.

La segunda caja igualmente con la nevera en icopor con hielo contenía, una pierna, toda la cadera, el corazón, el hígado, la cabeza sin orejas, una mano y en una bolsa pequeña una argolla de matrimonio con la inscripción Matilde Salcedo 20 de mayo de 1961, la cedula de ciudadanía de Jacinto Poveda y el pene de un hombre que había sido mordisqueado. La nota decía para el correcto amor y el moño era de color blanco.

El horror y el asco empezaron a notarse en los rostros de aquellos tres hombres, entre tanto el Dr. Montesino continuó describiendo con toda frialdad:

En la tercera caja, igualmente se encontró una nevera de icopor con hielo y el resto de lo que quedaba de este pobre hombre, el victimario, para su identificación dejo el otro testículo que al parecer había sido quemado con algún tipo de ácido y la libreta militar de Jacinto Poveda. La nota de esta caja decía de su pícaro amor y el moño era de color verde limón.

En conclusión puede de manera preliminar informarles que examine la sangre en el microscopio y es igual en las tres cajas, que el asesino quería que supiéramos quien era la víctima.

Aún queda por establecer, la identidad con las pruebas de ADN, pero ustedes saben que eso solo lo hacen en la capital y se demora como un mes, la causa del deceso y vincular la relación entre las tres mujeres que recibieron los supuestos regalos.

En la estación continuaban Mercedes, Matilde y Magdalena, consolándose entre sí, pues pensaban que era de muy mal gusto haberles hecho tan mala pasada. También estaba el locutor Flaminio Alza, y los gendarmes, el resto de gente había sido retirada por los gendarmes que estaban acuartelados para mantener el orden en las fiestas pero ante el suceso, se quedaron a controlar la curiosidad de la turba. Salieron por fin de la oficina el Alcalde, el Comandante, el Secretario del Juzgado Promiscuo Municipal y el Forense Montesinos, Barbosa tomo la vocería y dijo, señoras ustedes se quedan porque necesitamos hablar con cada una aparte. Por el momento de manera preliminar les podemos informar que es un solo cadáver, un solo muerto, que fue, desmembrado y repartido en tres y cada una de ustedes se les entregó una parte, en cada caja además de una de parte intima del hombre se encontraba un documento que lo identificaba, todos los documentos encontrados eran de la misma persona Jacinto Poveda.

Las tres mujeres gritaron horrorizadas, empezaron a llorar, la viuda Solís se desmallo, la confusión reino 
en ese momento.

El comandante intentó calmarlas gritándoles, que las pruebas de ADN, se demoraban casi un mes, pero que por los indicios parecía que era él, sin embargo que la profesora Matilde, tenía que ir y mirar el cuerpo cuando lograran armarlos para saber si era su esposo.

De paso el Alcalde autorizó al locutor Flaminio Alza, para que diera la noticia por la emisora y que además avisará que las festividades de San Pedro se cancelaban por la tragedia. Flaminio salió corriendo, pero la gente lo siguió, le preguntaban no lo dejaban caminar, un recorrido de dos minutos a paso normal, se convirtió en casi media hora y los gendarmes tuvieron que salir a colaborar con el comunicador.

Flaminio subió al estudio de la emisora, que estaba ubicada en el segundo piso del supermercado, "El Azulejo", tomó el micrófono y transmitió de siguiente noticia:

"Interrumpimos nuestra programación habitual para informarles una noticia de última hora. En la madrugada de hoy 29 de junio, fueron dejadas tres cajas de aparentes regalos que contenían los restos humanos, aparentemente de nuestro apreciado boticario Jacinto Poveda, que desapareció hace una semana de nuestra población. Está por confirmar su identidad pues debe armarse primero el cuerpo para que la profesora Matilde pueda reconocerlo, sin embargo, sus documentos estaban en las diferentes cajas al igual que sus partes íntimas dividas en los tres regalos. Esta noticia la ampliaremos apenas tengamos más información.

También la Alcaldía declara el duelo Municipal, y da por canceladas las fiestas de San Pedro, esto comprende, cabalgatas, muestras gastronómicas, conciertos y verbenas populares. El pueblo no está como para esas cosas. Continuamos con una programación especial para estos duros momentos."

La gente que estaba en la calle, escucho la noticia en los radios de las tiendas y tomaderos, restaurantes, supermercados. Las canchas de tejo y fritangueras empezaron a cerrar igual el resto de negocios, hasta las panaderías, el miedo y la zozobra acompañados de la música sacra que se empezó a transmitir el Azul Estéreo, terminaron de pintar de un tono grisáceo y turbio el ambiente.

El doctor Montesinos a sus 63 años paso toda esa noche trabajando al estilo Frankenstein, uniendo las partes del cuerpo, lo que nadie sabía era que después de ser un gran cirujano, a causa de una infidelidad de sus esposa había caído en las garras del alcohol y antes de cometer un error con uno de sus pacientes cambió su rumbo, y se dedicó mejor a los muertos, con eso si equivocaba más muerto no podía estar.

Hacia las nueve y media del otro día ya estaba listo el cadáver, así que mandó a llamar a la profesora Matilde para reconocerlo, ella que hacia escasas dos horas había llegado a su casa a dormir, pues toda la noche fue interrogada sobre la desaparición de su esposo y su relación con él, se levantó apurada tomo un tinto y en pijama con una ruano por encima atravesó la plaza del pueblo hasta la morgue.

Allí el Dr. Montesinos, el Comandante Barbosa y El Secretario, la esperaban, todos con sus rostros 
marcados por el cansancio ingresaron a la morgue, la sabana fue retirada del rostro del muerto, la profesora Matilde miro a un lado y al otro, con extrañeza se rasco la cabeza y dijo se parece mucho a mi marido, pero tiene una oreja más arriba que la otra, y le veo las cejas muy delgadas, depiladas, siguió bajando la sabana, por Dios, doctor las manos le quedaron al revés, pero sin duda son las manos de Jacinto, lo seguiré revisando por que como lo repartieron en tres, de pronto algo no pertenece a él, caramba ¿porque se le ve un testículo más grade que el otro, están raros?, pues aunque hace mucho que no intimábamos hasta donde me acuerdo los tenía iguales.

Montesinos les explicó que, uno había sido macerado y el otro quemado. Ante la explicación dijo serían las vagabundas, porque como se la pasaba allá, y a sus 53 quién sabe si les podía rendir o les quedó debiendo plata, y se soltó a reír cuando vio su miembro, se lo mordieron. Perdonen mi actitud, pero estas son cosas muy raras, pero también graciosas para el hombre más sin vergüenza de todo Puerto Azul, y tengan en cuentan que me case a los 19 años y ya tengo 41, dos hijos y quien sabe cuántas infidelidades le perdoné. Siguió mirando hacia abajo y preguntó por qué le falta una rodilla, no importa, doctor gírelo él tenía una mancha de nacimiento en una nalga.

Montesinos ayudado de su auxiliar lo giró y ella dijo, no hay duda, es Jacinto, pero porque le cocieron el culo, que vergüenza siendo farmaceuta y nunca pudo curar su problema de gases.

La profesora Matilde continuo diciendo, efectivamente es mi pobre marido, nunca entendió que llevar una vida tan desordenada lo llevaría a un terrible final, claro que yo imaginaba, que moriría a causa de una venérea o a manos de un marido celoso pero jamás así pedaciado y regado por todo el pueblo.

El comandante tomo del brazo a la maestra que en ese momento se veía alegremente perturbada, no parecía en sus cabales, al parecer la impresión la afecto a punto de chiflarla. Le preguntó, si estaba bien, a lo que ella contestó no lo sé, no que toca hacer ahora, dígame usted, ¿Llamo al cura, compro el cajón y el hueco en el cementerio?

El comandante le tomo la mano y le dijo: todavía no, el cuerpo el objeto de investigación igual tenemos que esperar los resultados de la capital. Qué pena que la moleste con algunas preguntas,

¿Por qué a pesar de todo lo que dijo adentro de la morgue jamás hablo mal de su esposo? Comandante las maestras de pueblo somos ejemplos para la comunidad y yo debía mantener mi imagen integra, a pesar de que todos superan las andanzas de mi marido; además que podía hacer separarme, eso no es bien visto. Me tocaba aguantar. ¿Qué más quiere saber comandante?, ¿Qué relación tiene usted con Mercedes y con doña Magdalena?

Cuando llegue nuevamente al pueblo de la normal alcance a darle clase a Mercedes, una buena niña y una buena muchacha, lo único es que no se sabe vestir parece una mujer de la vida, yo se lo he dicho cuando nos 
encontramos en el salón de belleza. Y con Magdalena, ella es la modista del pueblo, me hace los vestidos, hablábamos mucho siempre, ella me hizo mi vestido de quince años y de matrimonio, las sabanitas y las camisitas de mis hijos, es una gran amiga a pesar de sus 68 años ella sigue muy activa y se cuida mucho, igual también coincidimos a veces en el salón de belleza y charlamos.

En la casa de Matilde aguardaba en la puerta Flaminio el locutor, con un conmovedor saludo, le preguntó cómo le había ido a lo que ella contestó:

-Por desgracia mi marido es el descuartizado, a pesar de que al doctor Montesinos se le fueron las luces y le dejo una oreja arriba de la otra, una mano al revés, no apareció una rodilla y tenía el culo cocido, doy fe que ese era el cuerpo de Jacinto Poveda mi esposo.

Los días pasaban y en el pueblo todo empezaba a volver a la normalidad, aunque nadie volvió a salir después de la noche, ni a madrugar antes de las siete y media. Era un toque de queda autoimpuesto por el susto, hasta que no se encontrara al asesino nadie iba a descansar.

El comandante Barbosa continuaba con sus investigaciones pues la comisión de la fiscalía aun no llegaba, por aquello de la tramitología, visitó primero a Mercedes Barrera quien no había vuelto a trabajar hacía ya casi dos semanas, no se levantaba, estaba comiendo muy poco, sus padres estaban muy preocupados porque pensaron que el impacto del regalo del descuartizador la traumatizó de alguna manera.

Atendió en su cuarto al comandante a solas y en medio de muchas lágrimas le confesó a Barbosa que desde los quince años era amante de Jacinto Poveda, todo paso en la fiesta de la hija de él y la profesora Matilde, ella se fue a descansar un rato a una habitación y él llego allí, la sedujo, y ella quedó locamente enamorada de él. Cada mes ella pasaba por la droguería para que le pusiera la inyección para planificar y se veían de un tiempo para acá todos los jueves, su día de descanso, ella decía en su casa que iba hasta la vereda el Saladito donde vivían sus dos mejores amigas del colegio; pero en realidad solo pasaba por ahí un rato saludaba y seguía hacia Charco Verde, el pueblo vecino donde la esperaba Jacinto, pasaban el resto del día juntos y volvían el viernes en la mañana. El Boticario justificaba su ausencia diciendo que traería más drogas o encargos que le hacían. A ella le daba pena -dijo- con la profesora Matilde, su profesora, la que todavía le daba consejos como si fuera su hija; pero se enamoró de Poveda.

Barbosa tomó nota, y se retiró, esa tarde fue a la estación y transcribió la información para anexarla a expediente. Al día siguiente madrugo a la casa de la viuda Solís, la encontró vestida con los trajes de militar de su esposo fallecido, bebiendo y bailando, parecía que había dormido en días.

Señora Solís, como ha estado, comenzó Barbosa, a lo que ella contestó, -bien como me ve, feliz, recordando viejos tiempos,

El comandante enseguida se dio cuenta que estaba borracha, y le dijo, ¡viuda no le da pena a su edad en estas! 
Magdalena se reventó en risas, pena, pena, -dijo- Pena es la que me está matando, primero se murió mi marido, un infarto, mientras teníamos sexo, porque ese viejo militar me tenía mal acostumbrada desde que lo pensionaron lo hacíamos en la mañana, en la tarde y la noche muchas veces, pena, que voy donde el farmaceuta Jacinto, le cuento mi problema, que ya no puedo vivir sin estar con el macho al lado y me dijo que me iba a poner unas inyecciones para calmarme una en la mañana, una al medio día y una en la noche, y eso no funcionó así que el venia me ponía la inyección, se vestía con los trajes de mi marido y me complacía un ratico; eso sí jamás como mi marido; me prestaba el servicio completo y no me cobraba; y ahora quien sabe quién putas lo despresó como a un pollo y lo repartió entre las tres mujeres que estábamos con él, eso si da pena, pero pena moral, comandante Barbosa.

Abrumado ante tales confesiones de la ancianita dulce y respetada por todos, el comandante Barbosa se despidió de la ardiente viejita y se fue a transcribir la información. Al llegar a la estación se encontró con el resultado de las muestras de $\mathrm{ADN}$ que confirmaban que todas las partes eran del mismo cuerpo y el resultado de la carta de dental que confirmaba la identidad: Jacinto María Poveda Cristancho, 61 años, nacido 12 de Octubre en Puerto Azul.

Sorprendido por la agilidad en los resultados, salió hacia la escuela, saludo a la profesora Matilde y le contó que los resultados habían llegado, que podía empezar a organizar el sepelio. Ella encargó sus niños a Marujita otra maestra y se fue para la funeraria de Pepe y le aviso que había llegado el día, que llevará el cajón a la morgue. Luego paso a la iglesia y dijo lo propio al sacristán y por ultimo subió a la emisora y le pidió el favor a Flaminio que avisara que las exequias de Jacinto serian esa misma tarde hacia las cinco porque como llevaba más de dos semanas de muerto no era recomendable velarlo tanto tiempo, desde las dos estaría en la funeraria de don Pepe para los que se quisieran despedir.

Matilde parecía organizando más bien una fiesta, corrió a arreglar a sus hijos y se puso el vestido negro que le hizo Magdalena para la ocasión, le dijo a Genoveva su empleada que hiciera una ollada de sancocho, matara dos gallinas y le pusiera toda la carne de res y cerdo que quedaba en la nevera, mucha yuca y plátano verde como le gustaba a Jacinto para darle a los que nos acompañen, cuando esté le dice a los muchachos del vecino Martín que le ayuden a llevar la olla, los platos y las cucharas para donde Pepe.

Pasó al supermercado y pagó ocho canastas de cerveza, cinco botellas de aguardiente y cinco de ron para que las llevaran a la funeraria de Pepe.

Se dirigió luego al salón de belleza, y le dijo a la negra Celina, su confidente, la única que conocía sus penas, que la pusiera muy bonita para despedir al granuja de su marido por si todavía la podía ver, que se arrepienta de haberla engañado tantas veces. Celina se esmeró dejando a Matilde más que como una viuda como una novia, mientras la atendía hablaron largamente de cómo se sentía ahora, a lo que Matilde 
simplemente confesó, lo aliviada y agradecida que estaba con la muerte de su perro marido, el puerco infeliz, del desgraciado de Jacinto, pues ya no sería más el hazmerreír del pueblo y tampoco se expondría a contraer el tan de moda SIDA o cualquier otra enfermedad. Se abrazaron y Matilde salió a recoger la foto de Jacinto que mandó enmarcar para poner encima del cajón, pues como Montesinos lo reconstruyó tan mal, no quería que se burlaran de él, bueno más que por él, por la familia, los niños, los suegros, sus padres en fin, hermanos.

Al rato se encontraron en el salón de belleza, Mercedes y Magdalena, se saludaron cordialmente, y se arreglaron para la ocasión y así pasaron las también las prostitutas del pueblo y la madre del difunto y la suegra, más que un funeral era un evento.

A las dos y media no le cabía un alma a la Funeraria San Pedro de Pepe, solo había un muerto, pero parecía que todo el pueblo estaba allí. El Alcalde dio un emotivo discurso para levantar el ánimo del pueblo y quitar los miedos, que deambulaban de noche y madrugada por el caluroso Puerto Azul. La viuda profesora Matilde agradeció a todos y los invitó a comer y beber, como era de suponerse Genoveva preparo cinco olladas de metro y medio de sancocho rendidas con agua de vez en cuando, pero todos comieron y bebieron a la memoria de don Jacinto el farmaceuta que medicaba cuando no había médico rural, que aplicaba inyecciones, enyesaba esguinces y fracturas, solucionaba problemas de retrasos en las señoritas, además probo los néctares de más de una jovencita y con todas las prostitutas compró servicios.

Cuando se acercaban las cinco se acercaron las tres Emes al cajón y Magdalena todavía borracha, abrió la tapa del cajón y pego el grito, que desgracia, parece un mariquita le quitaron las cejas, y además una oreja más arriba que la otra, si era para cocer me debieron llamar a mí, porque Montesinos lo dejo como un payaso, la gente se alboroto y empezó el desfile de risas, porque con la barriga llena y corazón contento por el licor, lo que producía el pobre Jacinto era solo risas.

Los comentarios en medio de lo folclórico no se hicieron esperar, las mujeres lloraban y reían al tiempo, los niños también reían de ver reír, Matilde y su familia avergonzados en el segundo piso de la funeraria se escondieron. Para poder sacar al muerto de la funeraria y pasarlo al coche fúnebre y llevarlo a la iglesia fue necesaria la presencia de la policía nuevamente.

En la iglesia, hasta el cura quiso abrir la tapa del cajón para revisar el muerto, y soltó en risas, agregó "quedo como llevo su vida, desordenado", igual celebró la eucaristía, los alumnos de Matilde cantaron fue un momento angelical. Pero de camino al cementerio, el cielo se nubló, y como presagio de mala suerte empezó a llover la gente se dispersó, pues ya comidos, bebidos y divertidos no quedaba más que hacer allí y mojarse no valía la pena. Finalmente a Jacinto lo terminaron acompañando el cura y las tres Emes. Cerrada la tumba en silencio cada una tomo su camino.

Ya llegaba la fiesta de la Virgen del Carmen, y esa madrugada también se vio enrarecida por dos nuevos 
regalos, igual de grandes que los del San Pedro, el primero estaba frente al hospital, la tarjeta decía para la Lucia la mejor enfermera con un moño de color rojo, y el otro apareció frente al asadero de pollos, la tarjeta decía Carmencita la mejor cocinera del pueblo.

La noticia corrió como el viento, Flaminio transmitió el acontecimiento, un nuevo descuartizado, una mitad está en el hospital y la otra mitad en el asadero, la policía ya se acercaba a los lugares, de inmediato fueron a buscar al Dr. Montesinos, en esta ocasión nadie se atrevió a abrir las cajas, Lucia la enfermera del centro de salud llegó y al ver el tumulto pensó lo peor, entre tanto la policía fue a buscar a doña Carmencita a su casa para avisarle que en asadero había una caja como la del San Pedro, la mujer asustada se vistió y salió con su hijo mayor, le dijo al gendarme Pérez que su esposo, Segundo Macías, el lunes viajo a la Capital para surtir mercancía. De una vez anticipó que podía ser él.

Nadie abrió las cajas hasta que llegó el forense, don Pepe ya estaba en el lugar también, se llevaron las cajas para la morgue; Lucia y Carmencita fueron llevadas a la estación de policía.

El comandante Barbosa, ya con lo que había investigado del otro caso, relacionó inmediatamente que estas dos mujeres podrían estar compartiendo algo más que su apellido, pues Lucia y Carmencita eran hermanas de madre, Lucia Avendaño Guarín y Carmencita Prieto Guarín. El comandante vio que al encontrarse las dos mujeres estaban llorando pero no fueron muy calurosas en su saludo, como para ser hermanas.

Primero hizo entrar a su oficina a Carmencita, ella era una mujer muy bonita, algo gorda, pero su alegría y su buen genio le adornaban, tenía 38 años estaba casada con Segundo Macías, era la dueña del supermercado negocio atendido por su esposo y heredado de su papá y también le pertenecía el mejor restaurante asadero del pueblo, ella misma cocinaba y sus platos eran famosos, su capital lo consiguió por la herencia que le dejó su padre. Se casó a los 18 años cuando ya casi iba a dar a luz su hijo mayor, un desliz de colegio, y desde entonces segundo administra el supermercado.

El comandante fue al grano, le pregunto dónde estaba su esposo, a lo que ella respondió:

-como cada quince días viajando a la capital para surtir mercancía.

Pasó a preguntar la ha llamado, se ha comunicado con ella.

-No, él nunca me llama, se dedica a hacer vueltas y llega muy cansando al hotel donde se queda y madruga como se va solo por dos o tres días.

Barbosa notaba las similitudes, y paso a cuestionar, como se llevan ustedes, me refiero como pareja, él tiene otra mujer, o algo así, ¿me entiende Carmencita?

-No creo que tenga tiempo, pero igual nosotros hace varios años que más que esposos somos amigos, usted me entiende hasta compramos camas gemelas porque el ronca mucho y para no aguantarme las borracheras. 
El comandante agradeció a Carmencita y le dijo que se podía ir, que apenas hubiese noticias del forense la llamaba. Bueno comandante, pero si es mi marido por favor que lo remienden bien, para que la gente no se ría tanto esta vez por favor.

Barbosa llamo a Lucia, era una hermosa mujer de unos 40 años, esbelta y en su traje de enfermera se veía despampanante, tras pasar saliva, el comandante la invitó a sentarse y le pregunto cuál era su relación con Segundo, y mirándola a los ojos le dijo, además de cuñados, Lucia bajo la cabeza y le contestó:

-Segundo y yo nos conocimos en el colegio, era mi novio, y en una fiesta mi hermana Carmenza cuando lo vio borracho, lo engaño diciéndole que yo lo estaba esperando en la parte de atrás, se lo llevó y estuvo con el haciéndose pasar por mí, ella quedó en embarazo y mi padrastro los obligó a casarse. Yo me fui del pueblo a la capital cuando terminé el colegio y estudié enfermería, vine unas vacaciones y estuve hablando con Segundo y nos dimos cuenta que nos seguíamos amando, estuvimos juntos, yo no estaba preparada y quedé embarazada me devolví a la capital y seguí trabajando dos años más allá, se me acabo el contrato y me vine para acá con mi hijo pues no me salió trabajo rápido. Me quedé con mi mamá, le conté a Segundo que Clarita era su hija y él dijo que no quería que me fuera, y logró que me contrataran el centro de salud. Desde que volví somos amantes, pero sufro por su falta de carácter para separarse de mi hermana. Nadie sabe quién es el padre de mi hija, solo Segundo.

El comandante, asentó con la mirada tranquila Lucia, pero creo que se le ha complicado la vida, usted sabrá primero que yo cualquier dato que tenga Montesinos pero le reitero que estamos para esclarecer el caso y encontrar la verdad.

El comandante salió al tiempo con Lucia hacia el hospital, allí se encontraban Flaminio en espera de una noticia, el Juez Aguirre y el Alcalde. Salió Montesinos y los invitó a pasar y empezó:

Dos cajas de regalos, igual, don neveras de icopor con hielo en una caja se encuentra de cintura para arriba de un hombre y la otra de la cintura hacia abajo, me quedo más fácil cocer esta vez, en cada caja una bolsita en la primera una argolla de matrimonio marcada con el nombre de Carmencita, la libreta militar de Segundo Macías, un testículo aplastado y medio pene. En la otra caja una bolsita con la cédula de Segundo Macías, un testículo aplastado y medio pene.

En conclusión el muerto es Segundo Macías, lo coso y llamamos a la viuda que lo reconozca y empiecen a investigar quien está aplastándoles las güevas a los hombres del pueblo y se divierte cortándole el pito, no se esto debe ser algún loco, acaben pronto con esto porque si no los hombres terminaremos yéndonos a otro lugar.

Traigan a Carmencita, en una hora, para que mire lo que quedo de su marido.

Lucia entró a la morgue cuando vio que todos salieron, y rompió en llanto al reconocer el golpeado y 
maltratado cuerpo de su amante. Es Segundo.

Salió y le dijo a todos mataron a Segundo, Flaminio le confirmó esta segura señorita Lucia, a lo que ella en medio de lágrimas y abrazada a su cuello le dijo sí, estoy absolutamente segura.

Cuando Carmencita llegó a ver el cuerpo de Segundo, ya todo el pueblo sabía que él era el segundo descuartizado. El Juez Aguirre llamó insistentemente a la dirección de la Fiscalía porque apremiaba que enviaran los investigadores. Le contestaron que llegarían en dos días.

Entre tanto, las mujeres empezaron a alistarse para el funeral, don Pepe alistó todo, el cura preparado, y barra libre en el restaurante y en el supermercado. Carmencita contrató una serenata de mariachis del pueblo vecino, pues pensaba que debía despedir a su marido como a un héroe.

Entre tanto Lucia se fue a arreglar a salón de belleza de la negra Celina, estaba muy acongojada, Celina la escucho como siempre, ella era su paño de lágrimas, ella sabía que Segundo era el papá de Clarita, y también sabía que Segundo jamás dejaría a Carmencita aunque no la amara porque estaba acostumbrado a la buena vida, y sus viajes quincenales no eran solo de negocios sino también de lujuria pues en alguna ocasión que coincidieron en destino lo vio entrando a un burdel de mala muerte que quedaba cerca al terminal del transporte.

Celina le pregunto cómo se sentía a lo que ella contestó,

-Es raro, soñaba con irme lejos de acá con Segundo y la niña, pero después de revisar su historia clínica y sus múltiples tratamientos para combatir diferente enfermedades venéreas, ya no estaba tan segura. Creo que podré estar tranquila ahora, sin tener que explicar lo inexplicable, sin esperar lo que nunca sucedería.

Se abrazaron y se despidieron.

Al rato llego Carmencita, para que Celina le diera una manita, la actitud de ella era de tranquilidad, sin preguntarle fue contándole a Celina, que Segundo había sido el peor error de su vida, dañó su relación con su única hermana, hacía más de ocho años que nada de nada, cada uno en su cama, borracho, roncador y con venéreas, porque no habré estudiado mucho pero don Jacinto, que en paz descanse me explicaba para que servían los medicamentos que se tomaba. Yo todavía puedo rehacer mi vida. En verdad estoy agradecida con el descuartizador.

El 18 de Julio se realizaron las exequias de Jacinto a las once y media de mañana, las Guarín fueron las ultimas en marcharse del cementerio, se miraron a los ojos y ya con sus ojos cargados de tranquilidad se abrazaron como haciendo las pases y se marcharon de gancho hacia la casa de su madre.

Ese mismo 18 a las tres llegó el grupo de investigadores de la Fiscalía, el Agente, Ortiz y la Agente Orjuela, los llamaban el comando oxígeno, nunca dejaban un crimen sin resolver.

Se dirigieron hacia la estación de policía, hablaron con el comandante Barbosa, con los seis gendarmes, 
traían una grabadora del tamaño de un libro pequeño, y tomaban fotos que salían de una vez. Fueron a la morgue y encontraron al doctor Montesinos un poquito prendido, pues venía de las exequias de Segundo, no paraba de reír y se tambaleaba en la morgue de un lado al otro. Le solicitaron las pruebas, recopiladas, las cajas, los documentos, las pertenecías, en fin todo.

El galeno simplemente se sentó a reírse y les dijo no se dan cuenta en donde están, esta morgue solo tiene dos neveras, ósea dos muertos a la vez, mi laboratorio lo comparto con la bacterióloga del pueblo, muestras vivas con muertas, y ven algún espacio para guardar algo. Yo lave las pertenencias de los difuntos y se las di a las viudas. Que pensaron que estábamos en Hawái cinco cero y Barbosa es Magarret.

El comando oxígeno se retiró del lugar en medio del desconcierto y la risa, pues nunca habían abordado un caso sin pruebas, se sentaron en la fuente de soda de doña Luisa y se dedicaron a observar, y observaron por casi una semana entre limonada y limonada.

Luego de conocer las rutinas de los habitantes empezaron las entrevistas, retomaron las notas del comandante Barbosa, visitaron a las Emes y ratificaron sus versiones anteriores, visitaron a las hermanas Guarín y sucedió lo mismo, no había nada que hacer. Fueron al prostíbulo del pueblo y allí encontraron la primera pista, todas las chicas coincidieron en haber atendido a los dos difuntos por más de cinco años, que tanto Jacinto como Segundo tenían amantes además de sus esposas, que las amantes no se conocían entre sí, pero entendían su papel de segundonas y no les molestaba.

Entre ellas existía una cordialidad pues ninguna quería revelar su secreto, sus lugares comunes eran tres, la iglesia, la modista y el salón de belleza.

El comando oxigeno ya tenía por dónde empezar, primero visitaron al cura del pueblo como era de esperarse se amparó en el secreto de confesión para no dar información aunque por sus actitudes dejo entrever que si existía relaciones entre todas estas mujeres.

Fueron donde la viuda Solís, la modista y la encontraron borracha semidesnuda acompañada del sacristán de la iglesia. Sólo les dijo: Todas las mujeres hemos sido burladas por nuestros machos en algún momento de nuestras vidas, pero como eso no es un crimen pasa como si nada, menos mal aquí contamos con un descuartizador que nos hace justicia.

Un justiciero de las mujeres engañadas, ese parecía ser el asesino, sería un hombre, empezaron a pensar que tal vez no.

Esa tarde volvieron los dos investigadores a la estación para hablar con Barbosa y contarle sus hallazgos para saber qué opinaba finalmente el nació en ese pueblo y creció allí conocía a todos mejor que nadie.

Entre tanto Magdalena fue a visitar a la negra Celina y llamó a sus amigas para lo que se conocía como una tarde de belleza por las Emes y por las hermanas Guarín, también citaron a doña Lolita de Gutiérrez la esposa 
del alcalde, Marcela Escallón la secretaria del alcalde, Rosita Altamirano la directora de la escuela, Manuelita de Pérez, la esposa del gendarme, su prima Anadelia Marín, Jacinta Peñaranda y las trillizas González, en fin eran casi unas 30 mujeres reunidas en el patio trasero de la negra Celina.

Celina vestida con una túnica larga y un turbante, se levantó y dijo:

Bienvenidas hermanas de la legión contra la infidelidad, estamos en peligro ahora que hemos empezado a hacer justicia a nuestro dolor, a nuestra angustia, a nuestra destruida autoestima, quieren callar nuestras voces y detener nuestras acciones de justicia. Las reuní para que decidamos que hacer.

Se levantó la más creativa de las integrantes de la legión, la viuda Solís - divide y reinarás. En los ojos de esa investigadora vi que se acuesta con su compañero, hagámoslo caer en adulterio y ella terminará uniéndose a nosotras.

Pasadas tres semanas aparecieron dos nuevas cajas de regalo, una en prostíbulo con moño amarillo y una nota que decía para mi dulce gatita de su investigador favorito y la otra caja frente al hotel del pueblo con un moño rosado y una nota que decía para la mejor investigadora de su compañero.

Los descuartizados en Puerto Azul fueron desapareciendo, jamás se pudo establecer que sucedió y la Agente Orjuela viajaba cada vez que algo sucedía.

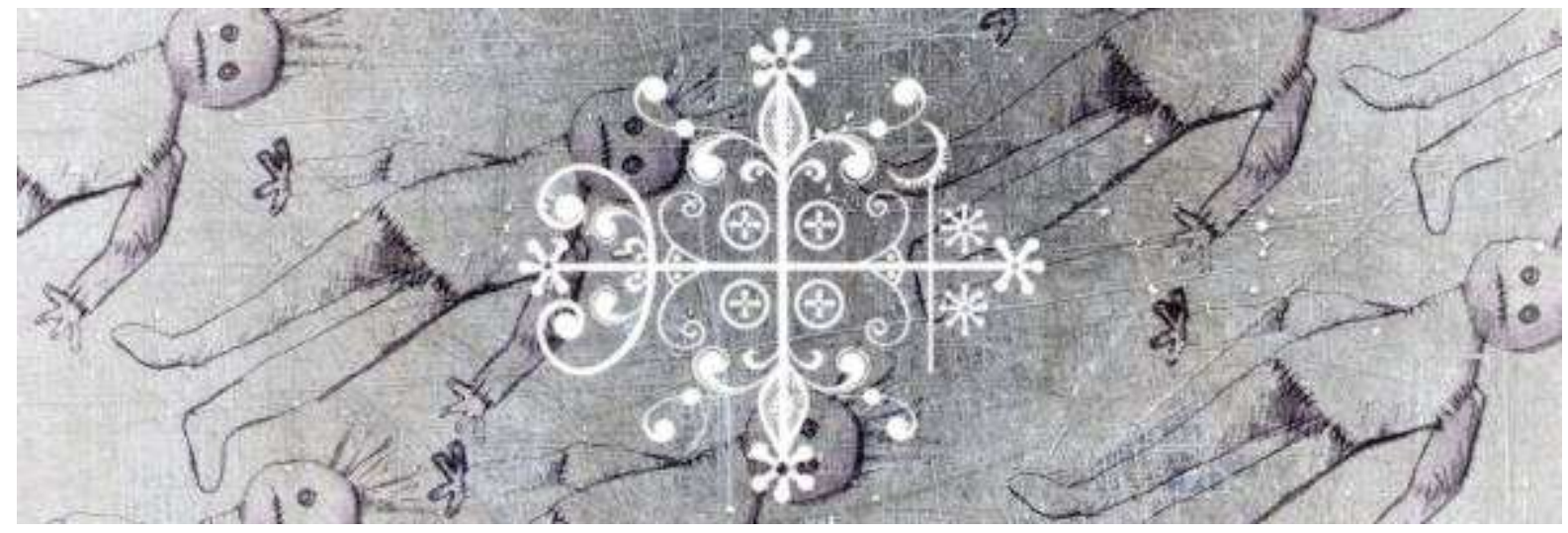

